\title{
Research on Spatial Pattern Dynamic Evolution Algorithm and Optimization Model Construction and Driving Mechanism of Provincial Tourism Eco-Efficiency in China under the Background of Cloud Computing
}

\author{
Fei Lu $\mathbb{D}^{1},{ }^{1}$ Wei Qin $\mathbb{D}^{2},{ }^{2}$ and Yu-Xuan Wang $\mathbb{D}^{3}$ \\ ${ }^{1}$ School of History, Culture and Tourism, Weifang University, Weifang 261061, China \\ ${ }^{2}$ School of Innovation and Entrepreneurship, Chongqing University of Posts and Telecommunications, Chongqing 400065, China \\ ${ }^{3}$ School of Economics \& Management, Beijing Forestry University, Beijing 100083, China \\ Correspondence should be addressed to Wei Qin; qinwei@cqupt.edu.cn
}

Received 19 July 2021; Revised 4 August 2021; Accepted 16 August 2021; Published 26 August 2021

Academic Editor: Punit Gupta

Copyright (C) 2021 Fei Lu et al. This is an open access article distributed under the Creative Commons Attribution License, which permits unrestricted use, distribution, and reproduction in any medium, provided the original work is properly cited.

Based on the research of spatial pattern dynamic evolution algorithm and optimization model construction and driving mechanism of provincial tourism eco-efficiency in China under the background of cloud computing, this paper takes 30 provinces in mainland China (excluding Tibet, Hong Kong, Macao, and Taiwan) as the research object and scientifically constructs the measurement index system of tourism eco-efficiency. The Super-SBM-Undesirable model is used to measure the tourism ecoefficiency of each province from 2004 to 2017, and the algorithm and model are optimized. This paper explores the spatial evolution trajectory and path of tourism eco-efficiency by using the barycentric standard deviation ellipse method and constructs a dynamic panel model to identify the factors affecting the evolution trajectory and their driving mechanisms by using the SYSGMM method. The results show that China's tourism eco-efficiency is at a high level and the eastern region is higher than the central and western regions. From the moving track of the center of gravity, the center of gravity of China's tourism eco-efficiency is located in Henan province, which has experienced a process of moving from southeast to northwest. From the standard deviation ellipse, the spatial distribution direction of China's tourism eco-efficiency presents a "northeast-southwest" pattern, and there is a further strengthening trend of deviation. There is a significant positive correlation between tourism eco-efficiency and tourism industrial structure upgrading, tourism industrial structure rationalization, tourism technology level, and tourism human capital, as well as a significant negative correlation between tourism eco-efficiency and tourism economic development level, environmental regulation intensity, and the degree of opening to the outside world, while the relationship between urbanization and tourism eco-efficiency is relatively vague.

\section{Introduction}

With the advent of the era of artificial intelligence and cloud computing, the future development of tourism service industry is closely related to artificial intelligence and cloud technology. Since the reform and opening up, the development of China's tourism industry has attracted worldwide attention and created tremendous economic and social value. At the same time, the tourism industry is also suffering from the huge impact of the rapid growth of regional economy. The impact of resource consumption and environmental pollution is prominent, which seriously hinders the transformation of China's tourism industry from highspeed growth to high-quality development stage [1]. During the period of the 13th Five-Year plan, Green Development has become the main theme of China's economic growth. How to seek the balance between tourism economic growth and environmental impact is the current focus of attention [2]. At the Second International Conference on Climate Change and Tourism, the Chinese government called on 
tourism-related departments in all regions of the world to actively take measures to save energy and reduce emissions. At the same time, the report of the 19th National Congress of the Communist Party of China raised the construction of ecological civilization to an unprecedented level, emphasizing that "the construction of ecological civilization can be considered as a millennium plan related to the sustainable development of the Chinese nation"; therefore, it is necessary to integrate the concept of Green Development into the whole process of tourism economic activities, optimize the structure of tourism industry, change the mode of tourism development, and realize the sustainable improvement of tourism economic growth and tourism environment. Visible, the impact of tourism on the ecological environment has attracted more and more attention. The tourism eco-efficiency is an important judgment index which reflects the two-way effect of the economic value of tourism and environmental impact and can objectively represent how to realize the efficient development of tourism under the background of Green Development, and it provides a new way to measure the level of tourism ecologicalization. Therefore, it is of great theoretical and practical significance to scientifically measure China's provincial tourism ecoefficiency and analyze its spatial pattern dynamic evolution characteristics and driving mechanism for formulating reasonable tourism development policies and promoting the coordinated development of tourism economy and ecological environment.

The idea of eco-efficiency dates back to the 1970s; German scholars Schaltegger and Sturm formally put forward the concept of eco-efficiency in 1990, which is defined as the ratio of economic value added to environmental impact [3]. Subsequently, a number of organizations have developed definitions, analyses, and extensions of eco-efficiency $[4,5]$, most notably the World Business Council for Sustainable Development (WBCSD), which proposes "creating maximum value with minimal environmental impact." With the development of research on tourism environmental impact, Gössling et al. derived tourism eco-efficiency from the idea of eco-efficiency and defined it as the amount of $\mathrm{CO}_{2}$ consumed per unit tourism economic value [6]. Since then, tourism eco-efficiency has attracted extensive attention of scholars and has made a wealth of effective research results. From the perspective of the research object, the research object of tourism eco-efficiency is gradually extended from various sectors and different tourism activities to the region, and more and more scholars study the tourism eco-efficiency from the regional perspective [7-9]. From the perspective of measuring methods, the method of measuring tourism eco-efficiency has been extended from single ratio method to DEA and its improved model method, and the methods and models of measuring tourism eco-efficiency have gradually matured and perfected [10]. From the research content, scholars gradually began to pay attention to the time series evolution, spatial pattern, and correlation change of tourism eco-efficiency [11] and, on this basis, use data model to analyze the formation mechanism and influencing factors of spatial-temporal differences of tourism eco-efficiency [12]. Generally speaking, although scholars have carried out in-depth discussion in the field of tourism eco-efficiency, a reference is provided for this paper. However, there are still some problems that need to be further developed: When using DEA and its improved model to measure tourism eco-efficiency, the treatment of undesired output does not conform to the process of tourism economy, and most of the nonexpected output indicators are based on tourism carbon emissions or tourism ecological footprint [13], and some are based on tourism "three wastes" emissions. At the same time, in the empirical analysis of the spatial-temporal evolution of regional tourism eco-efficiency at different scales, the existing literature explored its dynamic characteristics, failed to effectively reflect the spatial evolution characteristics and laws of tourism eco-efficiency, and revealed the influencing factors and mechanism of the evolution process. In view of this, this paper takes China's 30 provinces (excluding Tibet, Hong Kong, Macao, and Taiwan) as the research object and scientifically constructs the index system of tourism eco-efficiency, using Super-SBMUndesirable model to measure the eco-efficiency of tourism in various provinces from 2004 to 2017, and, on this basis, by means of the method of logarithmic deviation and gravity standard ellipse, to explore the spatial evolution track and path of tourism eco-efficiency, a dynamic panel model is constructed to identify the factors that influence the evolutionary track and its driving mechanism using SYS-GMM.

\section{Research Methods}

\subsection{Models}

2.1.1. Super-SBM-Undesirable Model. Common tourism eco-efficiency measurement models are mainly divided into parametric method and nonparametric analysis method. Compared with the parametric method, the nonparametric analysis method does not require a specific function form and residual distribution to explain the deterministic frontier production function. It is easy to apply and has many applications. The nonparametric deterministic frontier production function uses data envelopment analysis (DEA) as the basis. The DEA method is a "data-oriented" analysis method proposed by Charnes in 1978 to measure the relative efficiency of multiple inputs and multiple outputs. Because of the limitation of radial and angle, the traditional DEA model has deviation in efficiency Measure. Tone adds slack variable to the objective function and proposes a nonradial and nonangular SBM model, and the influence of radial and angle selection on efficiency measurement is effectively solved. At the same time, SBM model can also deal with the undesired output according to the production reality. Therefore, Tone extends the SBM model further and proposes an SBM model with undesired outputs [14]. In addition, the traditional DEA model cannot distinguish the differences among multiple DMUs (Decision Making Units) when the efficiency value is 1 . In view of this deficiency, Andersen and Petersen put forward the Super Efficiency DEA model which can distinguish the efficient DMUs [15]. The inefficiency of the measure is consistent with the traditional DEA, and the effective value is more 
than 1, so that the efficient DMUs can be distinguished. SBM model also has problems similar to those of the traditional DEA model. So, Tone extended SBM model, defined it as
Super Efficient SBM model, and compared and evaluated DMU which is in the front of production [16]. The model is constructed as follows:

$$
\begin{aligned}
\rho^{*} & =\min \frac{1+(1 / m) \sum_{i=1}^{m} s_{i}^{-} / x_{i k}}{1-\left(1 /\left(q_{1}+q_{2}\right)\right)\left(\sum_{r=1}^{q_{1}} s_{r}^{+} / y_{r k}+\sum_{t=1}^{q_{2}} s_{t}^{b-} / b_{t k}\right)}, \\
& \text { s.t. } \sum_{j=1, j \neq k}^{n} x_{i j} \lambda_{j}-s_{i}^{-} \leq x_{i k}, \quad i=1,2, \ldots, m, \\
& \sum_{j=1, j \neq k}^{n} y_{r j} \lambda_{j}+s_{r}^{+} \leq y_{r k}, \quad r-1,2, \ldots, q_{1}, \\
& \sum_{j=1, j \neq k}^{n} b_{t j} \lambda_{j}-s_{t}^{-} \leq b_{r k}, \quad k=1,2, \ldots, q_{2}, \\
& 1-\frac{1}{q_{1}+q_{2}}\left(\sum_{r=1}^{q_{1}} \frac{s_{r}^{+}}{y_{r k}}+\sum_{t=1}^{q_{2}} \frac{s_{t}^{b-}}{b_{t k}}\right)>0, \quad s^{-} \geq 0, s^{+} \geq 0, \lambda \geq 0, j=1,2, \ldots, n(j \neq k),
\end{aligned}
$$

where $\rho^{*}$ indicates the value of tourism eco-efficiency; $\lambda$ refers to the Weight Matrix; and $s^{-}, s^{+}$, and $s^{b-}$ represent the slack of input, expected output, and unexpected output, respectively.

2.1.2. Standard Deviation Ellipse. Standard deviational ellipse (SDE) is a spatial pattern statistical method, mainly used to analyze the global characteristics of the spatial distribution of geographic elements. The standard deviation ellipse is a statistical method of spatial pattern, which is mainly used to analyze the global characteristics of spatial distribution of geographical elements [17]. The gravity center, area, standard deviation of $x$-axis, standard deviation of $y$-axis, and rotation angle are the basic parameters of this method.

Gravity center is as follows:

$$
\begin{aligned}
& X=\frac{\sum_{i=1}^{n} R_{i} X_{i}}{\sum_{i=1}^{n} R_{i}} ; \\
& Y=\frac{\sum_{i=1}^{n} R_{i} Y_{i}}{\sum_{i=1}^{n} R_{i}} .
\end{aligned}
$$

Rotation angle is as follows:

$$
\tan \theta=\frac{\left(\sum_{i=1}^{n} R_{i}^{2} X_{i}^{* 2}-\sum_{i=1}^{n} R_{i}^{2} Y_{i}^{* 2}\right)+\sqrt{\left(\sum_{i=1}^{n} R_{i}^{2} X_{i}^{* 2}-\sum_{i=1}^{n} R_{i}^{2} Y_{i}^{* 2}\right)^{2}-4 \sum_{i=1}^{n} R_{i}^{2} X_{i}^{* 2} Y_{i}^{* 2}}}{2 \sum_{i=1}^{n} R_{i}^{2} X_{i}^{* 2} Y_{i}^{* 2}}
$$

Standard deviation of $x$-axis is as follows:

$$
\sigma_{x}=\sqrt{\frac{\sum_{i=1}^{n}\left(R_{i} X_{i}^{*} \cos \theta-R_{i} Y_{i}^{*} \sin \theta\right)^{2}}{\sum_{i=1}^{n} R_{i}^{2}}}
$$

Standard deviation of $y$-axis is as follows:

$$
\sigma_{y}=\sqrt{\frac{\sum_{i=1}^{n}\left(R_{i} X_{i}^{*} \sin \theta-R_{i} Y_{i}^{*} \cos \theta\right)^{2}}{\sum_{i=1}^{n} R_{i}^{2}}}
$$

where $(X, Y)$ is the gravity center of tourism eco-efficiency; $\left(X_{i}, Y_{i}\right)$ is the geographical center coordinate of province $i ; R_{i}$ is the attribute value of province $i$; $\left(X_{i}^{*}, Y_{i}^{*}\right)$ is the deviation of $\left(X_{i}, Y_{i}\right)$ from the ellipse center of province $i$; $\left(\sigma_{x}, \sigma_{y}\right)$ are the standard deviations of $x$-axis and $y$-axis; and the values of the major and minor axes of the ellipse.

2.1.3. Dynamic Panel Metering Model. Panel data has both cross-sectional dimension and time dimension, which can reflect heterogeneous factors (non-time-varying unobservable) and homogeneous factors (time-varying unobservable). Considering the economic inertia, the past economic behavior may have an impact on the current economic behavior. This paper chooses the dynamic panel econometric model. First, it can control the fixed effect; second, it can overcome the omission of variables; and, third, it can overcome the reverse causality problem. The general form of dynamic panel data model is as follows: 


$$
\operatorname{Ln} Y_{i, t}=\alpha+\beta Y_{i, t-1}+\gamma X_{i, t}+\varepsilon,
$$

where $\beta Y_{i, t-1}$ is lag tool variable and $\gamma$ is the regression coefficient that explains the variable.

\subsection{Index System Construction}

2.2.1. Index System of Tourism Eco-Efficiency Measurement. Referring to the existing research [18-20] and combining the tourism sustainable development theory and ecosystem theory, this paper constructs the index system of tourism eco-efficiency in China from three aspects of resources, economy, and environment. The input variables include tourism energy consumption, water resource consumption, tourism resource endowment, the number of tourism employees, and tourism capital input. The total tourism consumption and the number of tourism receptions are selected as the expected output, and tourism wastewater, $\mathrm{COD}$, ammonia nitrogen, $\mathrm{SO}_{2}$, smoke (powder) dust, $\mathrm{CO}_{2}$ emissions, and the amount of tourism garbage removal were used as undesired outputs. Among them, the tourism capital input is obtained by the method of perpetual inventory and the method of tourism capital stock estimation modified by $\mathrm{Wu}$ [21]; tourism resource endowment is determined by Zuo's scenic area weighting method [22]; the consumption of tourism water resources is calculated by using the regional input-output table and "tourism consumption stripping coefficient" [23]; by using the data of domestic and foreign tourists' consumption composition as well as the relevant data of regional input and output, the tourism energy consumption is separated from the specific industry by the "tourism consumption stripping coefficient" [24], and tourism $\mathrm{CO}_{2}$ emissions are then converted using the IPCC greenhouse gas emission inventory method. It should be noted that the various environmental impact assessments are not homogeneous in the tourism industry, so the entropy method is chosen to integrate the index.

2.2.2. Index of Influencing Factors. Integrating existing research and combining the particularity of tourism and the accessibility of tourism statistics, this paper identifies and analyzes the factors affecting the spatial dynamic evolution of tourism eco-efficiency by seven factors: the level of tourism economic development, the structure of tourism industrial, the technical level of tourism, the intensity of environmental regulation, the human capital of tourism, the degree of opening to the outside world, and urbanization. Specific indicators are shown in Table 1.

2.3. Data Source. All data come from "China Statistical Yearbook" (2005-2018), "China Tourism Statistical Yearbook (Original and Copy)" (2005-2017), "China Tourism Statistical Yearbook 2018," "Tourism Sampling Survey Data" (2006-2018), "China Energy Statistical Yearbook" (2005-2018), "China Population and Employment Statistical Yearbook" (2005-2018), "China Regional Economic Statistics Yearbook" (2005-2018), "China Water Resources Bulletin" (2005-2018)), "China Real Estate Statistical
Yearbook" (2005-2018), and the statistical bulletins of national economic and social development of various provinces, statistical bulletins of tourism industry, and statistical bulletins of tourism development from 2004 to 2017. For missing data in some provinces, the average growth rate method is used to fill in.

\section{Empirical Study}

3.1. Results of Tourism Eco-Efficiency Measurement. Based on the input-output data of tourism eco-efficiency in 30 provinces from 2004 to 2017, using the scale-return constant model of Super-SBM-Undesirable and using MaxDEA Ultra 8.1.2 to measure the tourism eco-efficiency of 30 provinces in the Chinese mainland, the results are shown in Table 2. The MaxDEA Ultra 8.20 software comes from Beijing Revomed Software Co., Ltd.

\subsection{Spatial Distribution Characteristics of Tourism} Eco-Efficiency. In order to explore the spatial differentiation characteristics of tourism eco-efficiency in different provinces of China, this paper selects four pieces of time-section data of tourism eco-efficiency in 2004, 2009, 2013, and 2017 and uses the software of ArcGIS 10.2 and draws the spatial distribution figure of China's tourism eco-efficiency (as shown in Figure 1). Based on the classification of ecoefficiency and tourism efficiency by Willard and Lu et al. [25] and combining with the research practice, the tourism ecoefficiency can be divided into five grades: high efficiency level (i.e., fully effective) $(\geq 1)$, near-high efficiency level (0.801-0.999), medium efficiency level (0.601-0.800), nearlow efficiency level $(0.401-0.600)$, and low efficiency level (0.101-0.400).

By analyzing the spatial distribution figure of tourism eco-efficiency, it is found that, in 2004, the tourism ecoefficiency of Beijing, Tianjin, Hebei, Shanxi, Shanghai, Jiangsu, Zhejiang, Anhui, Fujian, Jiangxi, Shandong, Henan, Chongqing, Sichuan, Guizhou, Yunnan, and Qinghai is in a completely effective state, accounting for $56.67 \%$ of all provinces; it is mainly distributed in the eastern coastal areas and southwest regions, while the rest of the provinces are at a higher level only in Hunan; Xinjiang and Gansu are at a very low level, and China's overall tourism eco-efficiency is at a higher level of efficiency. In 2009, 11 provinces, Tianjin, Hebei, Shanxi, Heilongiiang, Jiangsu, Anhui, Fujian, Shandong, Henan, Chongqing, and Guizhou, achieved full efficiency in terms of tourism eco-efficiency, accounting for $36.67 \%$ of all provinces, the high-value areas gradually showed a clear distribution of the eastern coastal areas, and tourism eco-efficiency of China in 2013 was relatively stable compared to that in 2009 , and the overall situation did not improve; the tourism eco-efficiency in Liaoning rose from a relatively low level in 2009 to a fully effective level, the medium level in Jiangxi and Shaanxi rose to a fully effective level, and Shanxi, Jiangsu, Anhui, and Henan dropped from a completely effective level to a relatively low level. In 2017, the four provinces of Hebei, Liaoning, Heilongjiang, and Shaanxi showed different degrees of decline in tourism 
TABLE 1: Index system of influencing factors.

\begin{tabular}{lcc}
\hline Influencing factors & Variable selection & Abbreviations \\
\hline Level of tourism economic development & Per capita income from tourism & ECON \\
Structure of tourism industry & Rationalization and optimization of tourism industry structure & SR, SO \\
Technical level of tourism industry & Energy consumption per unit of tourism income & TECH \\
Intensity of environmental regulation & Environmental Regulatory Strength Index & GR \\
Human capital of tourism & Average years of education & HUM \\
Degree of opening to the outside world & Operating income of foreign-funded star hotels/star hotels & OPEN \\
Urbanization & Urbanization rate & UR \\
\hline
\end{tabular}

TABLE 2: Measurement results of tourism eco-efficiency.

\begin{tabular}{|c|c|c|c|c|c|c|c|c|c|c|c|}
\hline \multirow{2}{*}{ Provinces } & \multicolumn{11}{|c|}{ Year } \\
\hline & 2004 & 2006 & 2008 & 2010 & 2011 & 2012 & 2013 & 2014 & 2015 & 2016 & 2017 \\
\hline Beijing & 1.098 & 1.098 & 0.367 & 1.002 & 0.373 & 0.335 & 0.410 & 0.378 & 0.336 & 0.338 & 0.372 \\
\hline Tianjin & 1.959 & 1.299 & 1.230 & 1.273 & 1.454 & 1.546 & 1.301 & 1.323 & 1.392 & 1.380 & 1.254 \\
\hline Hebei & 1.019 & 1.042 & 1.052 & 1.117 & 1.112 & 1.083 & 1.019 & 0.462 & 0.404 & 0.422 & 0.503 \\
\hline Shanxi & 1.090 & 1.076 & 0.450 & 0.617 & 0.435 & 0.413 & 0.531 & 0.574 & 1.005 & 1.075 & 1.168 \\
\hline Neimenggu & 0.470 & 0.527 & 0.408 & 0.297 & 0.266 & 0.239 & 0.265 & 0.286 & 0.255 & 0.327 & 0.345 \\
\hline Liaoning & 0.481 & 0.568 & 0.476 & 0.508 & 0.683 & 0.559 & 1.019 & 1.014 & 0.541 & 0.495 & 0.461 \\
\hline Jilin & 0.633 & 0.493 & 0.380 & 0.395 & 0.394 & 0.378 & 0.388 & 0.402 & 0.375 & 0.427 & 1.016 \\
\hline Heilongjiang & 0.678 & 0.732 & 0.729 & 1.122 & 1.086 & 1.130 & 1.132 & 0.252 & 0.290 & 0.272 & 0.331 \\
\hline Shanghai & 1.147 & 1.174 & 0.510 & 1.057 & 1.003 & 0.564 & 1.071 & 1.044 & 1.009 & 1.025 & 1.035 \\
\hline Jiangsu & 1.032 & 1.138 & 1.045 & 0.709 & 1.046 & 1.036 & 0.638 & 0.581 & 0.524 & 1.001 & 1.006 \\
\hline Zhejiang & 1.125 & 0.689 & 0.483 & 0.551 & 0.482 & 0.410 & 0.463 & 0.455 & 0.428 & 0.451 & 0.486 \\
\hline Anhui & 1.249 & 1.070 & 1.018 & 1.085 & 1.039 & 1.023 & 0.679 & 0.648 & 0.722 & 0.652 & 0.826 \\
\hline Fujian & 1.058 & 1.083 & 1.794 & 0.635 & 0.497 & 0.396 & 0.504 & 0.479 & 0.444 & 0.484 & 0.609 \\
\hline Jiangxi & 1.081 & 1.119 & 0.479 & 0.545 & 0.762 & 0.726 & 1.026 & 0.667 & 1.021 & 1.010 & 1.084 \\
\hline Shandong & 1.143 & 1.207 & 1.059 & 1.740 & 1.724 & 1.368 & 1.489 & 1.377 & 1.381 & 1.550 & 2.283 \\
\hline Henan & 1.059 & 1.230 & 1.333 & 1.106 & 1.073 & 1.024 & 1.071 & 1.084 & 1.063 & 1.108 & 1.119 \\
\hline Hubei & 0.616 & 0.598 & 0.439 & 1.019 & 0.540 & 0.485 & 0.629 & 0.576 & 0.524 & 0.558 & 0.648 \\
\hline Hunan & 0.853 & 0.555 & 0.501 & 0.527 & 0.482 & 0.454 & 0.540 & 0.460 & 0.484 & 0.461 & 0.742 \\
\hline Guangdong & 0.537 & 1.033 & 0.426 & 1.003 & 0.280 & 0.265 & 0.459 & 0.448 & 0.435 & 0.340 & 0.323 \\
\hline Guangxi & 0.517 & 0.508 & 0.360 & 0.408 & 0.439 & 0.425 & 0.541 & 0.484 & 0.460 & 0.541 & 0.653 \\
\hline Hainan & 0.399 & 0.314 & 0.200 & 0.063 & 0.205 & 0.189 & 0.177 & 0.169 & 0.181 & 0.285 & 0.293 \\
\hline Chongqing & 1.063 & 1.024 & 0.584 & 1.041 & 1.109 & 1.152 & 1.059 & 1.113 & 1.091 & 1.070 & 1.117 \\
\hline Sichuan & 1.024 & 1.070 & 0.485 & 0.517 & 0.642 & 0.453 & 0.592 & 0.707 & 0.519 & 0.474 & 0.474 \\
\hline Guizhou & 1.028 & 1.225 & 1.101 & 1.002 & 1.066 & 1.044 & 1.064 & 1.062 & 1.111 & 1.169 & 1.210 \\
\hline Yunnan & 1.444 & 1.040 & 0.376 & 0.321 & 0.306 & 0.284 & 0.351 & 0.366 & 1.371 & 0.466 & 1.023 \\
\hline Shaanxi & 0.411 & 0.717 & 0.469 & 0.693 & 1.056 & 1.030 & 1.010 & 0.755 & 0.542 & 0.595 & 0.770 \\
\hline Gansu & 0.360 & 0.339 & 0.226 & 0.288 & 0.281 & 0.281 & 0.294 & 0.306 & 0.309 & 0.332 & 0.417 \\
\hline Qinghai & 1.112 & 1.018 & 0.385 & 0.247 & 0.235 & 0.216 & 0.225 & 0.205 & 0.194 & 0.201 & 0.201 \\
\hline Ningxia & 0.513 & 0.384 & 0.290 & 0.350 & 0.304 & 0.329 & 0.281 & 0.231 & 0.193 & 0.242 & 0.435 \\
\hline Xinjiang & 0.370 & 0.255 & 0.153 & 0.191 & 0.165 & 0.157 & 0.164 & 0.156 & 0.145 & 0.153 & 1.284 \\
\hline The National & 0.886 & 0.854 & 0.627 & 0.714 & 0.685 & 0.633 & 0.680 & 0.602 & 0.625 & 0.630 & 0.783 \\
\hline Eastern China & 1.000 & 0.968 & 0.786 & 0.878 & 0.805 & 0.705 & 0.777 & 0.703 & 0.643 & 0.706 & 0.784 \\
\hline Central China & 0.907 & 0.859 & 0.666 & 0.802 & 0.726 & 0.704 & 0.750 & 0.583 & 0.685 & 0.695 & 0.867 \\
\hline Western China & 0.756 & 0.737 & 0.440 & 0.487 & 0.534 & 0.510 & 0.531 & 0.516 & 0.563 & 0.506 & 0.721 \\
\hline
\end{tabular}

Note. Not fully listed due to space limitation.

eco-efficiency, while Jiangsu and Yunnan returned to the state of full efficiency, and the overall level of China's tourism ecoefficiency has increased slightly. The regions with higher levels of tourism eco-efficiency are scattered in the three regions, and the differences among the regions are obvious.

\subsection{Characteristics of the Spatial Dynamic Pattern of Tourism} Eco-Efficiency. After defining the spatial distribution characteristics of China's tourism eco-efficiency, in order to understand the spatial dynamic pattern of China's tourism ecoefficiency, this paper analyzes its spatial pattern evolution by using gravity center and standard deviation ellipse. From the whole distribution of gravity center (as shown in Table 3), the moving path of the of gravity center of tourism eco-efficiency in China experienced the change of "southeast-northeast-northwest-southwest-northwest" during 2004 to 2017. From the three selected characteristic time points of 2004, 2009, 2013, and 2017, the gravity center is in Henan province. In the eastwest direction, the tourism eco-efficiency of the western 

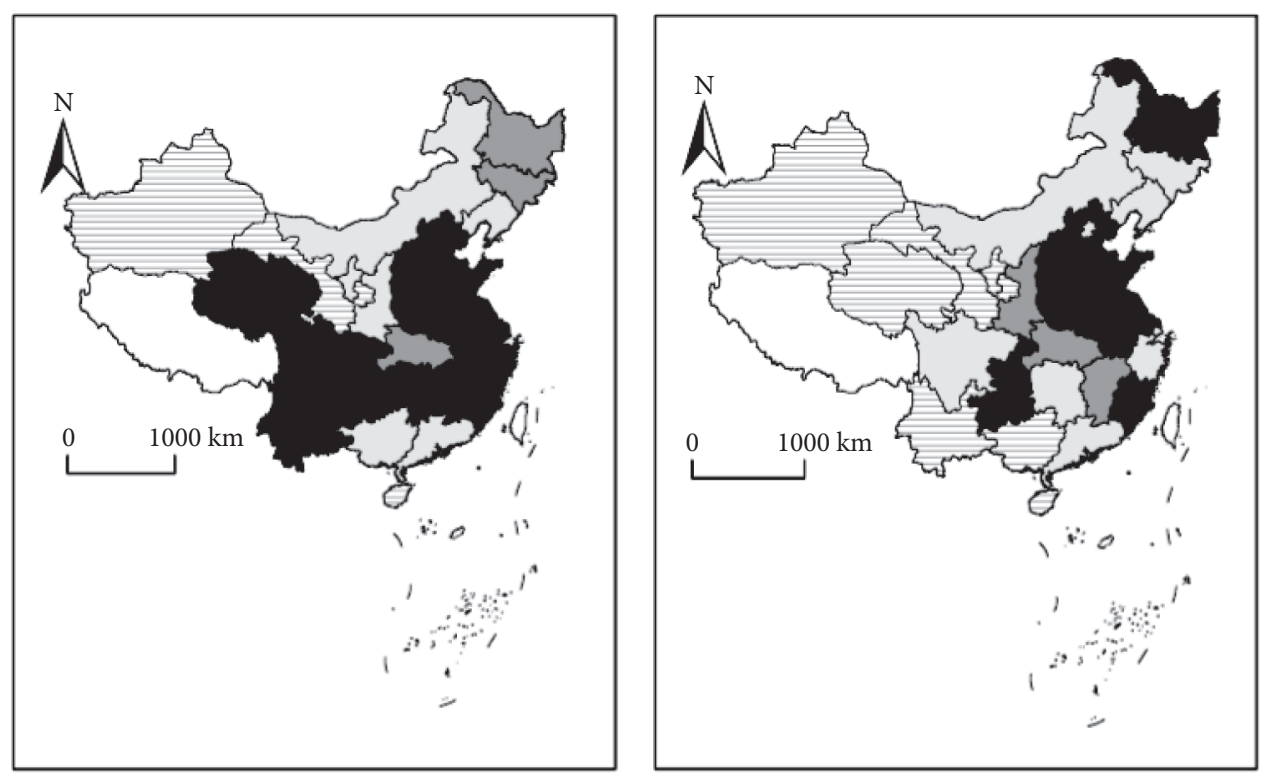

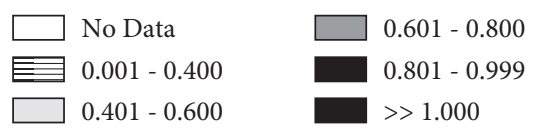

(a)

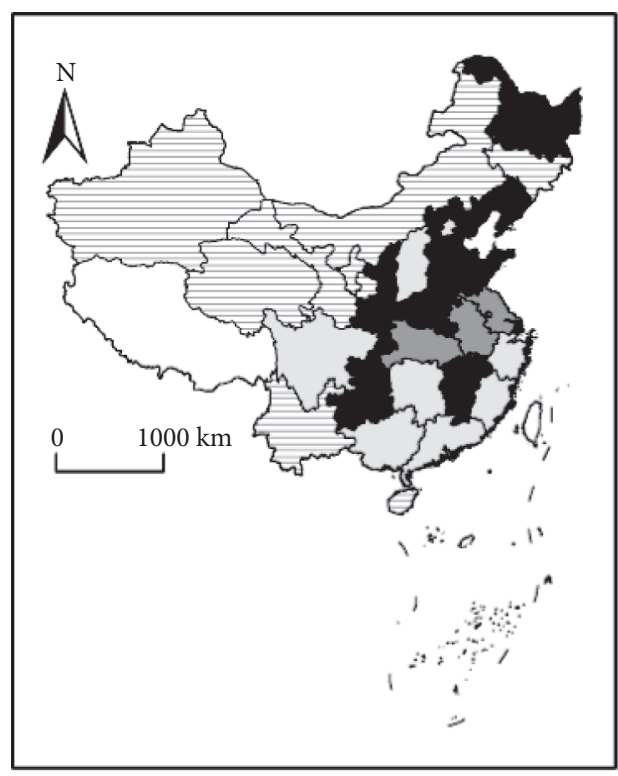

No Data

$0.001-0.400$

$0.401-0.600$

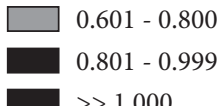

(c)

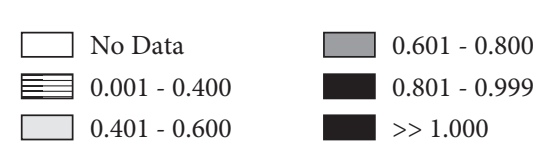

(b)
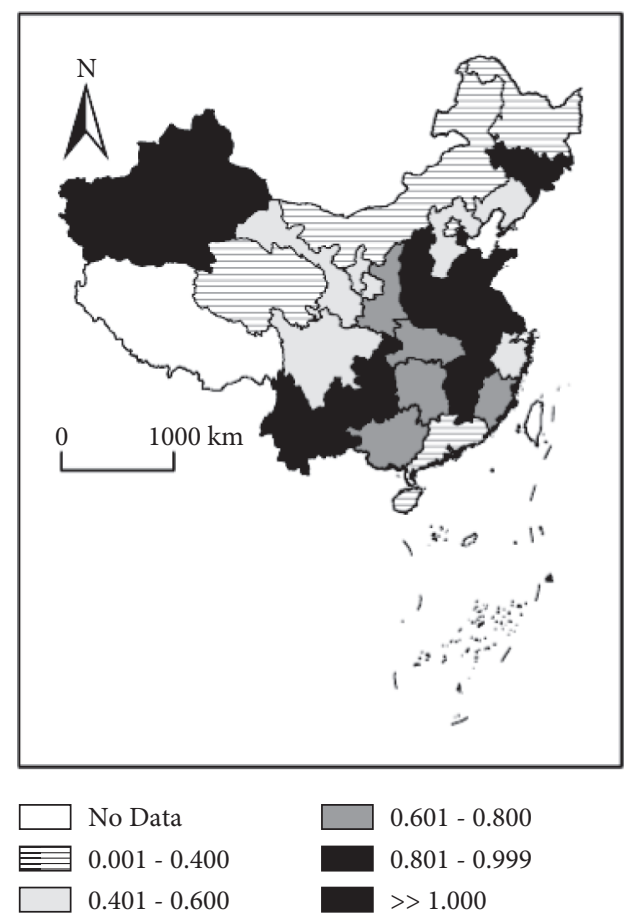

(d)

FIgURE 1: Spatial distribution of tourism eco-efficiency.

provinces is higher than that of other regional provinces. From the perspective of the moving direction of the gravity center, the gravity center of tourism eco-efficiency was near Nanzhao county, Nanyang, Henan province, in 2004. From 2004 to 2009, the gravity center gradually moved to the southeast, with a direction of $54.25^{\circ}$ southeast, the gravity center moved from Nanzhao county to Fangcheng county, and the gravity center of tourism eco-efficiency moved to the vicinity of Shangcai county, Zhumadian, with a shift direction of $6.13^{\circ}$ southeast in 2009-2013. Thus, the tourism eco-efficiency showed a trend of migration to the southeast from 2004 to 2013, indicating that the tourism eco-efficiency of the provinces in the southeast of China improved greatly during this period, which caused the gravity center to move to the southeast. After 2013, the gravity 
TABle 3: Direction and distance of the gravity center of tourism eco-efficiency.

\begin{tabular}{|c|c|c|c|c|c|c|c|c|}
\hline Year & Gravity center & Direction & $\begin{array}{l}\text { Moving distance } \\
(\mathrm{km})\end{array}$ & $\begin{array}{l}\text { East-west distance } \\
(\mathrm{km})\end{array}$ & $\begin{array}{l}\text { North-south } \\
\text { distance }(\mathrm{km})\end{array}$ & $\begin{array}{l}\text { Speed } \\
(\mathrm{km} / \mathrm{a})\end{array}$ & $\begin{array}{l}\text { East-west } \\
(\mathrm{km} / \mathrm{a})\end{array}$ & $\begin{array}{c}\text { North- } \\
\text { south } \\
(\mathrm{km} / \mathrm{a})\end{array}$ \\
\hline \multicolumn{9}{|l|}{2004} \\
\hline 2009 & $112.87^{\circ} \mathrm{E}, 33.37^{\circ} \mathrm{N}$ & $\begin{array}{c}\text { Southeast } \\
54.25^{\circ}\end{array}$ & 20.54 & 12.00 & 16.67 & 4.11 & 2.40 & 8.33 \\
\hline 2013 & $114.15^{\circ} \mathrm{E}, 33.23^{\circ} \mathrm{N}$ & Southeast $6.13^{\circ}$ & 143.62 & 142.80 & 15.34 & 28.72 & 35.70 & 3.84 \\
\hline 2017 & $112.27^{\circ} \mathrm{E}, 33.94^{\circ} \mathrm{N}$ & $\begin{array}{c}\text { Northwest } \\
20.54^{\circ} \\
\end{array}$ & 222.39 & 208.26 & 78.01 & 55.60 & 52.07 & 19.50 \\
\hline
\end{tabular}

center of tourism eco-efficiency began to move to the northwest and moved to Ruyang county of Luoyang, with a direction of $20.54^{\circ}$ northwest, which shows that the tourism eco-efficiency of the western region has improved greatly compared with the eastern and central regions during 2013 to 2017. From the perspective of distance and speed of gravity center movement, the distance and speed of gravity center movement of tourism eco-efficiency from 2004 to 2009 are the smallest, which are $20.54 \mathrm{~km}$ and $4.11 \mathrm{~km} / \mathrm{a}$, respectively. In 2009-2013, the speed of gravity center moving suddenly accelerated, the speed of east-west direction is $35.7 \mathrm{~km} / \mathrm{a}$, the speed of northsouth direction is $3.84 / \mathrm{a}$, and the speed of gravity center moving eastward is equivalent to the speed of gravity center moving as a whole $(28.27 \mathrm{~km} / \mathrm{a})$, which indicates that the gravity center of tourism ecological efficiency mainly moves eastward in 2009-2013, and the moving distance is $143.62 \mathrm{~km}$. From 2013 to 2017, the speed and distance of gravity center movement increased again, which were $4.11 \mathrm{~km} / \mathrm{a}$ and $222.39 \mathrm{~km}$, respectively. This is mainly due to the significant increase of the speed and distance of westward movement in the east-west direction, reaching $52.07 \mathrm{~km} / \mathrm{a}$ and $208.26 \mathrm{~km}$, respectively. On the whole, the moving speed of the center of gravity of tourism eco-efficiency continues to accelerate.

From the standard deviation ellipse of 4 years (as shown in Figure 2 and Table 4), the range of coverage from 2004 to 2017 is shrinking as a result of expansion. From 2004 to 2013, the standard deviation ellipse scope of tourism eco-efficiency showed a downward trend, and the area decreased from $300.45 \times 10^{4} \mathrm{~km}^{2}$ in 2004 to $253.00 \times 10^{4} \mathrm{~km}^{2}$ in 2013 , reaching the minimum value. Compared with 2004 , the space scope continuously reduced, the spatial agglomeration effect of tourism eco-efficiency of provinces in the interior of the standard deviation ellipse increases, but the spatial spillover effect is not obvious. In 2013-2017, the area of standard deviation ellipse increased from $253.00 \times 10^{4} \mathrm{~km}^{2}$ in 2013 to $341.83 \times 10^{4} \mathrm{~km}^{2}$ in 2017 . The area of standard deviation ellipse expanded in all directions, and the overall spatial distribution of tourism eco-efficiency tends to be scattered.

In the spatial direction (as shown in Table 4), the spatial direction of tourism eco-efficiency has two evolutional trends with 2009 as the cut-off point. From 2003 to 2009, the rotation angle $\theta$ decreased from $41.39^{\circ}$ to $26.83^{\circ}$, indicating that the space direction changed from "northeast-southwest" to "north-south". From 2009 to 2017, the rotation angle $\theta$ increased from $26.83^{\circ}$ to $72.95^{\circ}$, indicating that the space direction changed from "north-south" to "northeastsouthwest." On the whole, the spatial distribution of tourism eco-efficiency in China presents a pattern of "northeastsouthwest," and this pattern has a tendency of further strengthening.

\subsection{Driving Mechanism Analysis}

3.4.1. Panel Data Unit Root and Cointegration Test. The stationary and white noise of variables is the premise of panel data regression estimation; otherwise, it may lead to false regression or spurious regression, and the unit root test must be carried out for variable data. In order to prevent the error caused by the single test method, LLC Test, Breitung Test (for same root), IPS Test, Fisher-ADF Test, and FisherPP Test (for different root) are used in this paper. The results are shown in Table 5. LnTE, LnECON, LnSO, LnSR, LnTECH, LnGR, and LnOPEN all reject the null hypothesis of unit root at the $1 \%$ level in the 5 test methods, indicating that these 7 variables are all "integrated of order zero," while the sequence of LnHUM and LnUR is stationary after firstorder difference, indicating that these two variables are "integrated of order one." All variables are stationary after first-order difference. Therefore, all variables are "integrated of order one."

Variables must be of the same order, so that the panel data can pass the cointegration test. Therefore, the same order is the necessary condition of the panel data cointegration. On the premise of the same-order single integration after difference, it is possible to test whether there is a longterm cointegration relationship between panel data. In order to guarantee the reliability and robustness of cointegration test results, Modified Dickey-Fuller $t$-test, Dickey-Fuller $t$ test, Augmented Dickey-Fuller $t$-test, Unadjusted Modified Dickey-Fuller $t$-test, and Unadjusted Dickey-Fuller $t$-test in Kao test are used to test the cointegration of regression equations. It can be seen from Table 6 that all the statistical variables of the equations reject the original assumption that there is no cointegration relationship under the condition of $1 \%$; that is, there is a significant long-term stationary equilibrium relationship between the explanatory variables and the explanatory variables of the equations.

3.4.2. Selection of the Measurement Estimation Method. In terms of model regression for influencing factors, the model identified in this article has lags in the explained variables so as to avoid omitting the dynamics of the model and leading to biased results. At the same time, the explained 


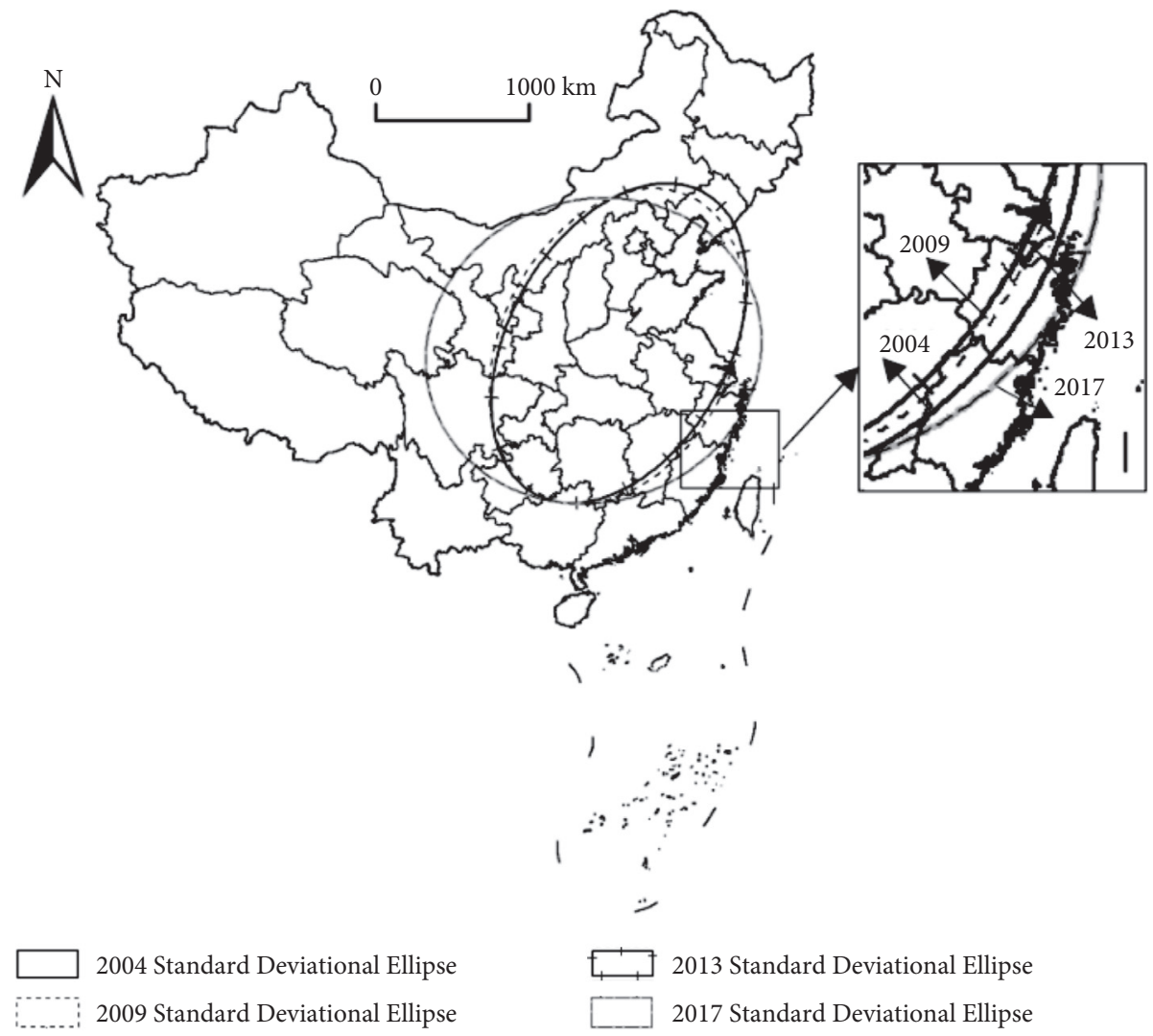

Figure 2: Standard deviation ellipse of tourism eco-efficiency.

TABLE 4: Standard deviation ellipse parameter of tourism eco-efficiency.

\begin{tabular}{lcccc}
\hline Year & 2004 & 2009 & 2013 & 2017 \\
\hline Rotation angle $\theta\left(^{\circ}\right)$ & 41.39 & 26.83 & 29.47 & 72.95 \\
Standard deviation of $x$-axis $(\mathrm{km})$ & 873.23 & 752.23 & 715.06 & 985.04 \\
Standard deviation of $y$-axis $(\mathrm{km})$ & 1095.25 & 1085.63 & 1126.33 & 1104.67 \\
Area $\left(\mathrm{km}^{2}\right)$ & $300.45 \times 10^{4}$ & $256.54 \times 10^{4}$ & $253.00 \times 10^{4}$ & $341.83 \times 10^{4}$ \\
\hline
\end{tabular}

TABLE 5: Unit root test for panel variables.

\begin{tabular}{lccccc}
\hline Variable & LLC Test & IPS Test & Breitung Test & Fisher-ADF Test & Fisher-PP Test \\
\hline LnTE & $-3.260^{* * *}(0.000)$ & $-2.816^{* * *}(0.002)$ & $-2.888^{* * *}(0.001)$ & $180.637^{* * *}(0.000)$ & $124.832^{* * *}(0.000)$ \\
LnECON & $-2.701^{* * *}(0.003)$ & $2.471^{* * *}(0.000)$ & $8.990^{* * *}(0.000)$ & $124.674^{* * *}(0.000)$ & $117.620^{* * *}(0.000)$ \\
LnSO & $-3.983^{* * *}(0.000)$ & $-0.147^{* * *}(0.004)$ & $3.191^{* * *}(0.000)$ & $130.885^{* * *}(0.000)$ & $53.779^{* * *}(0.000)$ \\
LnSR & $-8.066^{* * *}(0.000)$ & $-3.663^{* * *}(0.000)$ & $-2.785^{* * *}(0.002)$ & $217.317^{* * *}(0.000)$ & $195.529^{* * *}(0.000)$ \\
LnTECH & $-5.749^{* * *}(0.000)$ & $0.237^{*}(0.057)$ & $0.108^{* * *}(0.000)$ & $161.372^{* * *}(0.000)$ & $60.725^{* * *}(0.000)$ \\
LnGR & $-7.342^{* * *}(0.000)$ & $-7.856^{* * *}(0.000)$ & $-10.635^{* * *}(0.000)$ & $223.499^{* * *}(0.000)$ & $265.733^{* * *}(0.000)$ \\
D.LnHUM & $-8.093^{* * *}(0.000)$ & $-9.718^{* * *}(0.000)$ & $-12.054^{* * *}(0.000)$ & $183.122^{* * *}(0.000)$ & $474.034^{* * *}(0.000)$ \\
LnOPEN & $-22.938^{* * *}(0.000)$ & $-7.650^{* * *}(0.000)$ & $-7.586^{* * *}(0.000)$ & $281.887^{* * *}(0.000)$ & $263.000^{* * *}(0.000)$ \\
D.LnUR & $-2.833^{* * *}(0.002)$ & $-8.458^{* * *}(0.000)$ & $-3.199^{* * *}(0.007)$ & $139.882^{* * *}(0.000)$ & $478.798^{* * *}(0.000)$ \\
\hline
\end{tabular}

Note. ${ }^{*},{ }^{* *}$, and ${ }^{* * *}$ are significant at the levels of $10 \%, 5 \%$, and $1 \%$, respectively.

variables and the explanatory variables of the model have a causal relationship with each other, and there are endogenous problems. In dealing with endogenous problems, Manuel Arellano and Stephen Bond believe that the use of ordinary panel regression in the model will lead to deviations in the estimation results, which can be achieved through instrumental variable (IV) and generalized method of moments (GMM) to be eliminated. In the selection of instrumental variables, Anderson and Cheng rely on traditional methods to select instrumental variables that are not related to interference items and then first-order difference, selecting items lagging more than two orders as the instrumental variables of their difference items. Combined with the proposal of dynamic panel theory, differential 
TABLE 6: Panel cointegration test results.

\begin{tabular}{lcc}
\hline Test method & Value & $P$ value \\
\hline Modified $t$ & -9.278 & 0.001 \\
Dickey-Fuller $t$ & -13.71 & 0.001 \\
Augmented $t$ & -9.392 & 0.001 \\
Unadjusted Modified $t$ & -17.32 & 0.001 \\
Unadjusted $t$ & -15.88 & 0.001 \\
\hline
\end{tabular}

generalized moment estimation (Diff-GMM) and system generalized moment estimation (SYS-GMM) methods have become the mainstream of research. Diff-GMM uses difference to eliminate fixed effects and builds instrumental variables on the basis of difference equations, but the problem of weak instrumental variables cannot be solved. Furthermore, Arellano and Richard proposed the SYSGMM method, which starts with the information of difference and level equations to select instrumental variables. Compared with other methods, it can better solve the problem of endogeneity, and the model estimation results are also more effective. Based on the above analysis, this paper chooses the SYS-GMM estimation method to estimate the relevant factors of tourism eco-efficiency.

3.4.3. Model Estimates. Considering that SYS-GMM method selects instrumental variables from the information of difference and level equation, it can solve the endogeneity problem better than other methods, and the model estimation results are more effective. Therefore, SYS-GMM method was used for regression analysis in this paper, and the regression results are shown in Table 7 . As can be seen from Ward test, the set model is very significant. The Sargan test shows that the setting of the tool variable set is valid.

The regression results of Table 7 show that the tourism economic development level, which is expressed by per capita tourism income, has a negative effect on tourism ecoefficiency, and it is significant at $1 \%$ level. The rapid development of tourism economy has not brought about the rational allocation and utilization of resources and energy as well as the scale effect but inhibited the promotion of tourism eco-efficiency. The possible reason is that China's tourism economy is in a transitional stage, and the annual growth rate of tourism income is far higher than the average growth rate of China's GDP in the same period. With the rapid development of the tourism economy, unreasonable low-cost extensive development and operation mode gradually emerged.

The coefficient of tourism industry optimization (SO) passed the test on the level of $5 \%$ significance, which shows that the optimization of tourism industry structure has a positive and significant impact on tourism eco-efficiency. In view of the reality of the development of China's tourism industry, in recent years, driven by endogenous technology, the internal and external integration of the tourism industry ("tourism +") and other patterns have achieved a breakthrough in the innovation of tourism products, and its industrial added value has maintained long-term and steady growth; this technology upgrading and value-added growth
TABLE 7: Regression results of influencing factors.

\begin{tabular}{lc}
\hline Independent variable & LnTE \\
\hline L1. & $0.440^{* * *}(0.000)$ \\
LnECON & $-0.219^{* * *}(0.000)$ \\
LnSO & $0.012^{* *}(0.013)$ \\
LnSR & $0.070^{* *}(0.005)$ \\
LnTECH & $-0.603^{* * *}(0.000)$ \\
Wald test & $247.72^{* * *}(0.000)$ \\
Sargan test & 0.127 \\
LnGR & $-0.057^{* * *}(0.000)$ \\
LnHUM & $0.0394^{* * *}(0.002)$ \\
LnOPEN & $-0.002^{* * *}(0.008)$ \\
LnUR & $-0.150(0.667)$ \\
Cons & $1.196^{* * *}(0.000)$ \\
\hline
\end{tabular}

Note. ${ }^{*},{ }^{* *}$, and ${ }^{* * *}$ are significant at the levels of $10 \%, 5 \%$, and $1 \%$, respectively.

is the external performance of the structural adjustment of the tourism industry, which is beneficial to the energy-saving and emission reduction and environmental protection of tourism. The coefficient of tourism industry rationalization (SR) also passed the test at the significant level of 5\%, indicating that the rationalization of industrial structure has effectively promoted the eco-efficiency of tourism in China. It can be seen that the flow and reconfiguration of factors of production such as labor and capital among different economic sectors of tourism can effectively utilize all factors and bring about economic growth of tourism, but they do not cause resource depletion and ecological environment deterioration.

The technical level of tourism industry represented by the energy consumption per unit tourism income is a negative indicator. The higher the energy consumption per unit tourism income, the lower the technical level of tourism industry. Its coefficient is obviously negative, which fully shows that enhancing the technical level of tourism is an important way to improve the eco-efficiency of tourism. On the one hand, technological progress can be conducive to the promotion of advanced ecological production and the improvement of energy and resource efficiency of tourism enterprises; on the other hand, technological progress can promote pollution reduction and treatment technologies so as to improve the end of pollution control capacity and further promote the generation of clean energy.

The impact of environmental regulation intensity on tourism eco-efficiency is negative, and it has passed the significance test. The possible reasons for the failure of the government's environmental regulation are as follows: Firstly, the relevant environmental policies and measures formulated by the government have not been effectively implemented, there is a lack of supervision, and it cannot effectively correct the negative externalities of environmental pollution in various sectors related to tourism. Secondly, the cost of effective implementation of environmental regulation is too large and the government intervention is difficult to grasp, which leads to the decrease of the coordination between the economic growth of tourism and the development of ecological environment. Thirdly, due to the traditional development concept, the extensive 
development mode of China's tourism industry has not changed in essence. Compared with developed countries, the intensity of environmental regulation is still relatively low, and the innovation effect of environmental regulation has not been effectively triggered.

The effect of tourism human capital on tourism ecoefficiency is positive at the significance level of $1 \%$. The main reason is that the education level can, to a certain extent, reflect the social environmental protection consciousness, and environmental protection consciousness enhancement helps consciously perform the obligation of environmental protection; at the same time, tourism practitioners are the higher level of education, and professional skills and technical innovation ability are higher, which is good for energy saving and "three wastes" emissions.

The impact coefficient of the degree of opening to the outside world on tourism eco-efficiency is negative and significant. The amount of foreign investment in tourism reflects the region's ability to attract foreign investment in some aspects, but it is not conducive to improving the regional tourism eco-efficiency. The following are the possible reasons: Firstly, the foreign investment to consider more for tourism is China's rich tourism resources, vast market and its cheap labor supply, foreign investment in the process of actual operation, and the development of tourism resources using a double standard only for the purpose of economic interests of predatory development brought about great pressure to the ecological environment. Secondly, the purpose of China's introduction of foreign capital is to consider the structural and technological effects of foreign investment and the "spillover effect" of management experience and eco-production techniques as well as the "demonstration effect" of high standards of environmental protection brought about in the process of promoting employment and economic development in the region, thus promoting the structural transformation and upgrading of local tourism industry; however, the ecological damage and environmental pollution caused by pollution-intensive foreign capital inflow offset the benefits to some extent. Finally, some local governments relax environmental regulation in order to attract foreign investment in tourism and promote the development of tourism economy at the expense of the environment, thus restraining the promotion of tourism ecoefficiency.

\section{Conclusion and Discussion}

4.1. Conclusion. In this paper, the Super-SBM-Undesirable model is used to measure the tourism eco-efficiency of 30 provinces in China from 2004 to 2017. On the basis of clarifying the spatial distribution characteristics of tourism eco-efficiency, this paper explores the spatial evolution track and path of tourism eco-efficiency with the help of the the method of gravity center and standard deviation ellipse, constructs a dynamic panel model, and uses SYS-GMM to identify the factors influencing the evolution track and its driving mechanism. The results are as follows: Firstly, during the study period, the overall eco-efficiency of tourism in China is at a high level, and the eastern region is higher than the central and western regions. The provinces with higher tourism eco-efficiency are scattered in three regions, with obvious differences in each region. Secondly, from 2004 to 2017, the gravity center of China's tourism eco-efficiency is distributed in Henan province, and its movement track is "Nanyang (Nanzhao county)-Nanyang (Fangcheng county)Zhumadian (Shangcai county)-Luoyang (Ruyang county)," the change pattern of the gravity center is first to the southeast and then to the northwest, and the moving speed of the center of gravity is continuously accelerating. Thirdly, from the perspective of the standard deviation ellipse, the overall spatial distribution pattern of China's tourism ecoefficiency tends to disperse, and the rotation angle shows a process of "shrinking a little, increasing a little, then increasing"; the result shows that the spatial distribution of China's tourism eco-efficiency shows a pattern inclined northeast-southwest and has the trend of further strengthening. Fourthly, the optimization of tourism industry structure, the rationalization of tourism industry structure, the technical level of tourism industry, and tourism human capital are positively correlated to tourism eco-efficiency; the development level of tourism economy, the intensity of environmental regulation, and the degree of opening to the outside world are negatively related to tourism eco-efficiency, while the relationship between urbanization and tourism eco-efficiency is ambiguous.

4.2. Policy Implications. In order to promote the sound and coordinated development of China's provincial tourism industry and ecological environment and promote the highquality development of tourism economy, the following policy recommendations are put forward: First, we should put the protection of tourism ecological environment in a prominent position in combination with the current big data analysis and research and promote the process of nationalization of ecological civilization theory education, as well as change the evaluation index system of tourism development only based on total tourism revenue and tourist receptions. Second, we should combine big data artificial intelligence technology to promote the precise coordination of the allocation of tourism industry elements and comprehensively weigh the impact of tourism economic growth and ecological environment deterioration brought about by the flow of technology, capital, information, labor, and other factors, increase the proportion of green, circular, and lowcarbon economy in the tourism industrial structure, and promote the coordinated development of various economic sectors of tourism, as well as comprehensive use of tourism industry planning and policy means to optimize and integrate tourism production factors from the source, while effectively supplying, to avoid duplication of factors, blind investment, and overcapacity. Thirdly, combined with the development of artificial intelligence technology, precise, informationized, and scientific economic policies such as finance and taxation should be adopted to provide support for tourism enterprises adopting advanced ecological technology, accelerate the pace of popularizing pollution control and prevention technology, gradually establish energy statistics and auditing system for tourism industry, and 
encourage the development of energy-saving and consumption-reducing tourism enterprises. Moreover, we should improve the access standards of foreign investment in tourism industry, change from attracting investment to selecting investment, and select appropriate technologies consistent with the regional tourism economic development environment so as to improve the utilization efficiency of advanced ecological management and technology. Finally, we will make full use of the strictest eco-environmental protection system in the National New-Type Urbanization Plan (2014-2020) and continue to strengthen the construction of tourism eco-environment and improve the efficiency of tourism eco-environment under the mechanism of green, circular, and low-carbon development. The planning of urbanization should consider the present situation of tourism ecological carrying capacity, enhance the support of Environmental Protection Industry, comprehensively study the change characteristics of regional wind direction and the location of tourism service facilities, and rationally plan and arrange the industrial location. Combining the tourism planning with the urbanization ecological planning and on the basis of the tourism planning, setting out a single ecological control index to guide the development and construction of tourism, it also plans energy-saving and emission reduction targets for water-saving rate, rainwater utilization rate, and carbon emission rate of tourism service facilities. The corresponding indicators of tourism ecological response indicators will be brought into the government performance appraisal, improve tourism infrastructure, fully tap the consumption potential of regional tourism market, and vigorously develop green tourism and ecotourism.

4.3. Discussion. Based on the theory of sustainable tourism development and the theory of ecosystem, this paper attempts to construct an index system for the measurement of China's provincial tourism eco-efficiency in order to comprehensively evaluate China's tourism eco-efficiency and to study the dynamic evolution of the spatial pattern of China's tourism eco-efficiency and its driving mechanism by means of artificial intelligence thinking logic, geographical methods, and dynamic panel model. However, there are still some shortcomings to be further explored: on the one hand, the input-output indicators of tourism industry involved in the measurement index system of tourism eco-efficiency are quantifiable indicators. Some social and environmental indicators that are difficult to quantify are not involved, and it is assumed that environmental pollution is homogeneous and stable in all industries. On the other hand, due to the strong correlation of tourism industry, the influencing factors of the spatial dynamic pattern evolution of tourism eco-efficiency are very complex, and it is difficult to fully cover the selection of indicators, and it is impossible to cover all the influencing factors in the regression model. In this sense, the results of empirical analysis in this paper cannot fully explain the actual situation but only have statistical significance in probability. Therefore, in the future, more variables should be included in the theoretical analysis model in the process of factor analysis.

\section{Data Availability}

Data sharing is not applicable to this article as no datasets were generated or analyzed during the current study.

\section{Conflicts of Interest}

The authors declare no conflicts of interest with respect to the research, authorship, and/or publication of this article.

\section{Acknowledgments}

This work was supported by Weifang University Phd Foundation Project (2021SB43).

\section{References}

[1] P. Wu and S. Yue, "Research progress on energy demand and carbon dioxide emission of tourism industry," Tourism Tribune, vol. 28, no. 7, pp. 64-72, 2013.

[2] Y. Ma and J. Liu, "The core value and promotion strategy of tourism ecological efficiency under the background of green development," Tourism Tribune, vol. 31, no. 9, pp. 1-3, 2016.

[3] S. Schaltegger and A. Sturm, "Ökologische rationalität: ansatzpunkte zur ausgestaltung von ökologieorientierten managementinstrumenten," Unternehmung, vol. 44, no. 4, pp. 273-290, 1990.

[4] R. Côté, A. Booth, and B. Louis, "Eco-efficiency and SMEs in nova scotia, Canada," Journal of Cleaner Production, vol. 14, no. 6, pp. 542-550, 2006.

[5] M. Braungart, W. Mcdonough, and A. Bollinger, "Cradleto-cradle design: creating healthy emissions - a strategy for eco-effective product and system design," Journal of Cleaner Production, vol. 15, no. 13, pp. 1337-1348, 2007.

[6] S. Gössling, P. Peeters, J.-P. Ceron et al., "The eco-efficiency of tourism," Ecological Economics, vol. 54, no. 4, pp. 417-434, 2005.

[7] H. S. Peng, J. .H. Zhang, Y. Han, G. R. Tang, and Y. Zhang, "SBM-DEA model and empirical analysis of tourism destination ecological efficiency measurement," Acta Ecologica Sinica, vol. 37, no. 2, pp. 628-638, 2017.

[8] W. .K. Lin and B. Lin, "Evaluation of ecological efficiency of regional tourism industry and its spatial difference: a case study of Jiangxi Province," East China EconomicManagement, vol. 32, no. 6, pp. 19-25, 2018.

[9] Z. G. Yao, T. Chen, S. .B. Yin, and X. G. Li, "Empirical analysis of regional tourism ecological efficiency: a case study of Hainan Province," Geographic Science, vol. 36, no. 3, pp. 417-423, 2016.

[10] P. Sabine, S. Ana, and S. Matthias, "The greenhouse gas intensity of the tourism sector: the case of Switzerland," Environmental Science \& Policy, vol. 13, no. 2, pp. 131-140, 2010.

[11] H. Cheng, Q. Xu, and M. Y. Zhao, "Research on spatial correlation network structure and its influencing factors of tourism ecological efficiency in China," Ecological Science, vol. 39, no. 5, pp. 169-178, 2020.

[12] Z. F. Wang and Q. F. Liu, "Spatiotemporal evolution of tourism eco efficiency in the Yangtze River economic belt and its interaction with tourism economy," Journal of Natural Resources, vol. 34, no. 9, pp. 1945-1961, 2019.

[13] M. Lenzen, Y. Y. Sun, F. Faturay et al., "The carbon footprint of global tourism," Nature Climate Change, vol. 8, no. 6, pp. 522-544, 2018. 
[14] K. Tone, "A slacks-based measure of efficiency in data envelopment analysis," European Journal of Operational Research, vol. 130, no. 3, pp. 498-509, 2001.

[15] P. Andersen and N. C. Petersen, "A procedure for ranking efficient units in data envelopment analysis," Management Science, vol. 39, no. 10, pp. 1261-1264, 1993.

[16] K. Tone, "A slacks-based measure of super-efficiency in data envelopment analysis," European Journal of Operational Research, vol. 143, no. 1, pp. 32-41, 2002.

[17] A. Mamuse, A. Porwal, O. Kreuzer et al., "A new method for spatial centrographic analysis of mineral deposit clusters," Ore Geology Reviews, vol. 36, no. 4, pp. 293-305, 2009.

[18] J. P. Cha, "Development efficiency, emission reduction potential and emission reduction path of China's low carbon Tourism," Tourism Tribune, vol. 31, no. 9, pp. 101-112, 2016.

[19] J. Liu, L. Huang, L. J. Wu et al., "Study on direct and virtual water consumption of rural tourism in Qingcheng Houshan heritage site," Tourism Tribune, vol. 9, pp. 108-116, 2018.

[20] J. Liu and Y. Ma, "Perspective of sustainable tourism development: a review of tourism ecological efficiency," Tourism Tribune, vol. 32, no. 9, pp. 47-56, 2017.

[21] Y. M. Wu, "Spatial panel econometric analysis of tourism economic growth and its spillover effect," Tourism Tribune, vol. 29, no. 2, pp. 16-24, 2014.

[22] B. Zuo, "Analysis on growth factors and contribution of China's tourism economy," Business Economy and Management, vol. 10, pp. 82-90, 2011.

[23] J. F. Li and M. Y. Li, "Calculation of tourism industry and tourism added value," Tourism Tribune, vol. 5, pp. 16-19+76, 1999.

[24] J. Liu and Q. Y. Song, "Spatial network structure and formation mechanism of green innovation efficiency of China's tourism industry," China Population, Resources and Environment, vol. 28, no. 8, pp. 127-137, 2018.

[25] L. W. Lu, D. Y. Song, and X. F. Li, "Research on green efficiency of urban development in Yangtze River economic belt," China Population, Resources and Environment, vol. 26, no. 6 , pp. 35-42, 2016. 